\title{
Management of hereditary breast and ovarian cancer: The Asian experience
}

\author{
Ava Kwong* \\ Chairman and Founder of The Hong Kong Hereditary Breast Cancer Family Registry \\ and Hong Kong Hereditary and High Risk Breast Cancer Programme, Assistant \\ Dean, Associate Professor and Chief of Breast Surgery, Department of Surgery, \\ The University of Hong Kong, Chief of Breast Surgery, Hong Kong University \\ Shenzhen Hospital
}

DOI: http://dx.doi.org/10.19106/JMedScieSup004804201608

\section{ABSTRACT}

$B R C A 1 / B R C A 2$ mutations are the most common high-penetrant genes associated with increased lifetime risk for hereditary breast and ovarian cancer (HBOC). Although genetic testing is included in standard of care in Western developed countries, there are still variations of its availability and risk assessment for $\mathrm{HBOC}$ in Asia. The clinical strategies and cancer management varies by country across Asia. The Asian BRCA Consortium has gathered information from 14 Asian countries to review genetic counselling/testing uptake rates and clinical management options in these countries. In addition, economic factors, healthcare and legal frameworks, and cultural issues affecting the genetic service availability in Asia were discussed. Mutation spectrum, VUS rates, and the increase use of NGS gene panel testing pose a decisional issue in the clinical management of Hereditary Breast cancer in Asia, these issues would be discussed here as well.

Keywords: BRCA1/BRCA2, germline, HBOC, Asia BRCA Consortium, NGS 